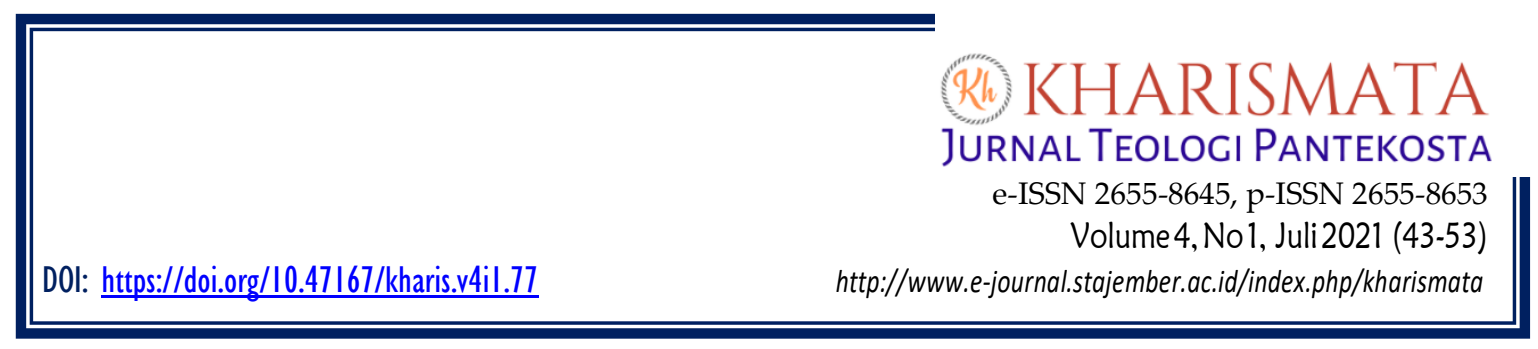

\title{
Missio Dei dalam Konteks Indonesia: Analisis Naratif Matius 18:15-17 sebagai Misi Allah bagi Gereja
}

\author{
Hanry Chandra1, Grant Nixon², Martina Novalina ${ }^{3}$ \\ 1,2,3Sekolah Tinggi Teologi Ekumene, Jakarta \\ 1hanry@sttekumene.ac.id,2grant.nixon@sttekumene.ac.id \\ ${ }^{3}$ martina@sttekumene.ac.id,
}

\begin{abstract}
The Church is a fellowship of the sinners who have accepted Jesus Christ as Lord and saviour. Ironically, even after receiving forgiveness of sin, congregations are still human beings who still have the potential to do sin or mistake. It can happen to anyone, whether he is a church member, servant, or even pastor. Besides that, sin and mistake can happen in multiple forms and places, internally or externally. This article itself is an effort to find a biblical formulation in order to face this reality within the church ministry. This formulation can be found within Matthew 18:15-17 which contains a special discourse in Matthew concerning the church. The Church often understands Missio Dei or God's mission only for non-Christian. According to this research, by using a descriptive-analytical method toward Matthew 18:15-17, which is a proportional hermeneutic approach, there seems a concept that Missio Dei also goes to Christians who live in sin. God loves sinners and because of that, He arranges how a Christian community faces its members who did sin. In this case, Matthew 18:15-17 teaches a concept that Missio Dei happens in multidimensional, including the one who has known God, yet falls in sin again.
\end{abstract}

Keywords: church; Matthew 18:15-17; mission; missio Dei

\begin{abstract}
Abstrak. Pemahaman Missio Dei yang terlalu terpusat pada gereja cenderung menempatkan sasarannya atas bangsa-bangsa yang belum terjangkau Injil atau daerah-daerah yang belum pernah dijelajah. Hal ini menyebabkan perhatian Missio Dei sangat dominan pada usaha konversi. Mereka yang telah terhisab dalam gereja dipandang sebagai "yang telah ditemukan", sehingga tidak lagi menjadi sasaran utama dalam pembahasan misi. Padahal penekanan pada usaha konversi semacam ini dapat menjadi tantangan tersendiri dalam misi konteks Asia, terutama Indonesia. Melalui penelitian dengan menggunakan metode deskriptif analitis terhadap Matius 18:15-17, yaitu melalui pendekatan hermeneutik yang proporsional, ditemukan suatu konsep bahwa Missio Dei berlaku juga bagi mereka yang sudah Kristen namun jatuh dalam dosa. Allah mengasihi orang berdosa dan oleh sebab itu, Ia mengatur bagaimana komunitas Kristen menghadapi jemaat yang berbuat dosa. Dengan kata lain, teks Matius 18:15-17 mengajarkan satu konsep bahwa Missio Dei berlaku dalam berbagai dimensi, termasuk bagi orang-orang Kristen yang sudah mengenal Allah, namun berbuat dosa lagi.
\end{abstract}

Kata kunci: gereja; Matius 18:15-17; misi; missio Dei 


\section{PENDAHULUAN}

Gereja adalah kumpulan orang-orang yang telah dipanggil dari kegelapan menuju terang Tuhan yang ajaib menjadi satu tubuh dalam-Nya. ${ }^{1}$ Dengan kata lain, gereja adalah kumpulan orang-orang yang telah ditebus dari dosa melalui karya pengorbanan Yesus. Realitanya, karya penebusan ini tidak menghilangkan potensi manusia dalam berbuat dosa. ${ }^{2}$ Setiap orang Kristen, apa pun latar belakangnya memiliki pergumulan yang sama; pergumulan untuk hidup benar dalam bayang-bayang potensi dosa. Oleh sebab itu dikenal sebuah tahapan hidup kristen yang dikenal dengan nama sanctification atau pengudusan. Pada tahapan ini, orang-orang Kristen harus belajar untuk mengalahkan potensi dosa dan berusaha melakukan kebenaran dengan pertolongan Roh Kudus.

Dengan menyadari realitas potensi dosa orang-orang Kristen tanpa memandang latar belakangnya, gereja perlu menetapkan sebuah respons bilamana dosa terjadi di tengah jemaat. Hal ini diperlukan karena potensi dosa dimiliki oleh orang semua orang tanpa memandang jabatan gerejawi atau bahkan pengetahuan teologinya. ${ }^{3}$ Tidak peduli jemaat, aktivis atau bahkan pendeta sekalipun, semuanya memiliki potensi yang sama dalam melakukan dosa. Itulah sebabnya pertanyaan penelitian yang mendasari penelitian ini adalah, apakah yang harus dilakukan oleh gereja jika ada salah satu anggotanya, apapun jabatannya, melakukan dosa?

Penetapan countermeasure ini tentu diperlukan agar ada sebuah acuan dasar dalam mengambil sikap ketika ada salah satu anggota gereja melakukan dosa. Penetapan ini tentu tidak berlebihan mengingat potensi dosa itu benar-benar nyata dan pasti terjadi. Dengan demikian countermeasure untuk menanggulangi persoalan dosa ketika itu terjadi mutlak diperlukan. Dengan adanya countermeasure ini, praktik main hakim sendiri yang subyektif dapat dihindari. Selain itu, kepemilikan countermeasure ini akan menjadi acuan bahwa gereja dikelola dengan baik dan penuh tanggung jawab, baik di hadapan Tuhan, maupun di hadapan jemaat.

Penelitian ini adalah sebuah upaya untuk membangun counter measure tersebut. Dalam hal ini, penulis akan menggunakan teks Matius 18:15-18 sebagai landasan dalam membangun konsep. Teks ini dipilih karena memiliki relevansi yang jelas dan dapat digunakan sebagai landasan biblika dalam membangun konsep Missio Dei bagi jemaat yang berdosa yang diusung penulis. Missio Dei adalah konsep yang dilahirkan dari Konferensi Misionaris Internasional pada bulan Juli tahun 1952. Menurut Hartenstein, pengutusan Anak untuk mendamaikan dunia melalui kuasa Roh Kudus adalah landasan misi. Dalam hal ini, Missio Ecclesiae (misi gereja) berasal dari Missio Dei. Dengan demikian Missio Dei ingin menegaskan bahwa menegaskan karya kesela-

\footnotetext{
${ }^{1}$ Michael J Anthony, “THE HEART OF GOD AND THE CHURCH,” Bibliotheca sacra 176, no. 704 (October 2019): 387-399, http://www.dts.edu/ (Publisher's URL:).

${ }^{2}$ A E (Agbonkhianmeghe Emmanuel) Orobator, "Between Ecclesiology and Ethics: Promoting a Culture of Protection and Care in Church and Society," Theological Studies 80, no. 4 (December 2019): 897-915, http://tsj.sagepub.com/ (Subscriber access).

3 J Schipper, "The Anchor Yale Bible," 2008.
} 
matan Allah (misi Allah) diwujudkan melalui Gereja. ${ }^{4}$

Di sisi lain, pemahaman Missio Dei yang terlalu terpusat pada gereja ini cenderung menempatkan sasarannya atas bangsa-bangsa yang belum terjangkau Injil atau daerah-daerah yang belum pernah dijelajah. ${ }^{5} \mathrm{Hal}$ ini menyebabkan perhatian Missio Dei sangat dominan pada usaha konversi. Mereka yang telah terhisab dalam gereja dipandang sebagai "yang telah ditemukan", sehingga tidak lagi menjadi sasaran utama dalam pembahasan misi. Padahal penekanan pada usaha konversi semacam ini dapat menjadi tantangan tersendiri dalam misi konteks Asia, terutama Indonesia.

Dalam misi konteks Korea, Soo-il mengungkap bahwa model misi yang dibawa oleh Barat dalam kerangka Missio Dei-nya memiliki keterbatasan tertentu pada misi konteks Korea yang harus diselesaikan. ${ }^{6}$ Keterbatasan tersebut berupa konteks politik, sosial, budaya masyarakat Korea yang berada di bawah opresi dari penjajahan kala itu. Selain itu, kepercayaan dan agama di Asia yang beragam telah hidup berdampingan sejak lama. Keragaman tersebut tidak mudah diselesaikan hanya dengan konversi ala kolonial dalam perjumpaannya. Dibutuhkan dialog dan ruang bagi keragaman dalam masyarakat Asia yang majemuk. Untuk menjawab keterbatasan tersebut, dibutuhkan adaptasi teologis dalam pemaknaan misi, terutama dalam hubungan gereja dengan dirinya sendiri dan masyarakat. Soo-il mengajukan konsep bermisi yang bertumpu pada pembebasan yang merangkul dan menciptakan ruang beragama baru, ketimbang konversi yang mengeliminasi keberadaan pihak lain. Dengan demikian, Soo-il memanggil para teolog untuk mengadakan pemaknaan ulang yang lebih luas mengenai Missio Dei bagi negara-negara Asia yang memiliki konteks politik, sosial, budaya yang partikular. Untuk menyikapi hal tersebut, penelitian ini menempatkan Missio Dei pada konteks yang lebih luas guna menjawab permasalahan kontekstual di Indonesia.

Indonesia pada konteks kini berbeda dengan konteks pada masa kolonial. Pada masa kini, Indonesia telah memiliki ratusan sinode yang diakui pemerintah. Dengan jumlah yang semakin bertambah, kompleksitas berjemaat juga semakin meningkat dan menuntut suatu pendekatan yang serius. Penelitian Bilangan Research menunjukkan bahwa gereja memiliki permasalahan internal dalam membangun budaya keterbukaan terhadap jemaat bermasalah, terutama ketika harus berjumpa dengan kaum muda yang dinamis dan partikular dibanding generasi sebelumnya. ${ }^{7}$ Sebanyak 61,8\% remaja merasa bahwa gereja telah tidak menarik dan tidak cocok bagi mereka karena alasan internal pula, seperti buruknya kepemimpinan, banyaknya kepurapuraan, banyaknya kegiatan yang lebih menarik di luar gereja, sampai pada bentuk

\footnotetext{
${ }^{4}$ Wilhelm Richebächer, "MISSIO DEI: THE BASIS OF MISSION THEOLOGY OR A WRONG PATH?," International Review of Mission 92, no. 367 (October 2003): 588-605.

5 Tormod Engelsviken, "MISSIO DEI : THE UNDERSTANDING AND MISUNDERSTANDING OF A THEOLOGICAL CONCEPT IN EUROPEAN CHURCHES AND MISSIOLOGY," International Review of Mission 92, no. 367 (October 2003): 481-497.

${ }^{6}$ Chai Soo-il, "MISSIO DEI-ITS DEVELOPMENT AND LIMITATIONS IN KOREA," International Review of Mission 92, no. 367 (October 2003): 538-549.

7 “Dinamika Hidup Generasi Muda Kristen Indonesia," accessed May 10, 2021, http://bilanganresearch.com/dinamika-hidup-generasi-muda-kristen-indonesia.html.
} 
ibadah yang tidak lagi menarik. Merujuk pada permasalahan internal ini, konsep Missio Dei tentu harus dimaknai ulang dalam konteks yang lebih luas, yakni bukan hanya di luar gereja, namun juga di dalam tubuh gereja sendiri.

Menjawab perluasan konsep Missio Dei, kami menentukan lokus biblika yang berporos pada mekanisme penjangkauan karya Allah di tengah umat-Nya dalam Matius 18:15-18. Dalam hal ini, teks Alkitab adalah sumber utama untuk membangun konsep misi yang baik bagi masa lalu dan juga masa kini. ${ }^{8}$ Selanjutnya, pemilihan teks ini didasarkan pada dua argumentasi. Pertama, teks Matius 18:15-18 berada dalam rangkain pengajaran khusus dalam Matius, yaitu pengajaran soal jemaat. Dengan demikian pengajaran ini sangat relevan mengingat perhatian penelitian ini adalah gereja secara khusus. Selain itu, alasan kedua adalah bahwa isi dari pengajaran dalam teks ini adalah persoalan dosa jemaat. Itulah sebabnya penulis menggunakan teks ini sebagai landasan dalam menyusun konsep Missio Dei terhadap potensi jemaat dalam melakukan dosa.

\section{METODE}

Penelitian ini akan menggunakan metode kualitatif melalui pendekatan studi literatur dalam bingkai hermeneutik yang proporsional. Proporsional di sini berarti menggunakan berbagai macam analisis hermeneutik secara integratif untuk menemukan makna teks yang terkandung dalam Matius 18:15-18. Setelah makna teks ditemukan, penulis akan mengolahnya menjadi sebuah konsep dan kemudian akan langsung ditarik relevansinya ke dalam konteks pembaca modern (gereja saat ini dalam pelayanan pastoralnya). Langkah serupa telah diterapkan oleh Johannes Knoetze ${ }^{9}$ yang memandang bahwa missio Dei merupakan sebuah gerakan ke luar sekaligus ke dalam. Dalam konteks Afrika, Knoetze mengartikulasikan ulang konsep missio Dei sebagai konsep yang menjangkau keluarga dan lingkungan pastoral gereja sebagai lingkaran penting dalam misi di Afrika. Dengan demikian artikel ini akan berusaha memberi perspektif bahwa penjangkauan jemaat yang berdosa harus dipandang sebagai bagian integral yang tidak dapat dipisahkan di samping penjangkauan ke luar gereja yang selama ini menjadi jantung misi konteks Indonesia. Melalui metode ini, diharapkan konsep Missio Dei terhadap jemaat yang berdosa dalam gereja dapat dirumuskan secara sistematis dan dapat dipertanggungjawabkan secara hermeneutis.

\section{HASIL DAN PEMBAHASAN}

Seperti yang sudah dibahas sebelumnya, penelitian ini akan berpusat pada penggalian makna teks Matius 18:15-18 yang kemudian akan ditarik relevansinya ke dalam konteks sekarang. Oleh sebab itu, penulis akan memaparkan latar belakang

\footnotetext{
${ }^{8}$ Fransiskus Irwan Widjaja, Fredy Simanjuntak, and Noh Ibrahim Boiliu, "Repositioning Mission in Postmodern Culture," in Proceedings of the 1st International Conference on Education, Society, Economy, Humanity and Environment (ICESHE 2019) (Presented at the 1st International Conference on Education, Society, Economy, Humanity and Environment (ICESHE 2019), Tarutung, Indonesia: Atlantis Press, 2020), accessed June 19, 2021, https://www.atlantis-press.com/article/125936174.

$9 \mathrm{~J}$ Knoetze, "Perspectives on Family and Youth Ministry Embedded in the Missio Dei - an African Perspective," Die Skriflig/In Luce Verbi 49, no. 1 (2015): 9, https://doi.org/10.4102/ids.v49i1.1874.
} 
ringkas mengenai lahirnya teks Mat. 18:15-18. Perlu diketahui, teks ini berada dalam rangkaian pengajaran keempat dalam Injil Matius yaitu, pengajaran tentang kehidupan jemaat atau gereja10. Dalam hal ini, konsep manajemen dosa dalam jemaat lahir setelah teks perumpamaan tentang domba yang hilang (Mat. 18:10-14). Perumpamaan ini dengan gamblang ingin menegaskan kehendak Allah yang tidak ingin satu pun dari domba (jemaat) terhilang atau berada di luar persekutuan dengan Allah. Hal ini secara kontekstual mengindikasikan fokus pengajaran dalam bagian ini ingin memberikan perhatian lebih kepada persoalan dosa dalam perspektif Missio Dei. Allah digambarkan seperti seorang gembala yang keluar dan menjalankan misiNya dengan jalan mencari, menemukan, dan menyelamatkan domba (jemaat) yang hilang. Itulah sebabnya, penulis akan menggali makna teks dan menarik relevansi dengan menggunakan kaidah-kaidah hermeneutik yang integratif terhadap masing-masing ayat dalam Matius 18:15-18.

\section{Pendekatan Personal}

Matius 18:15, dapat disusun seperti ini:

Jika saudaramu berdosa kepadamu (klausa kondisional)

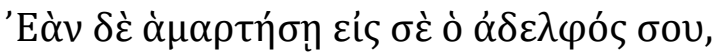

pergi dan tegurlah dia antara kamu dan dia saja (klausa imperatif)

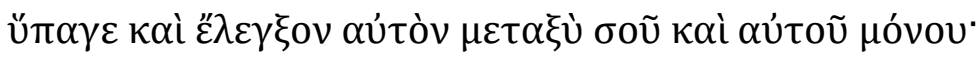

Jika dia mendengarkanmu (klausa kondisional)

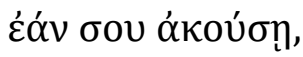

kamu mendapatkan saudaramu (klausa indikatif)

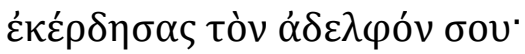

Berdasarkan analisa struktur kalimat di atas, terlihat jelas bahwa teks ini memiliki struktur kalimat yang tertata rapi. Teks ini dimulai dengan kata hubung 'Eò v dan kata kerja $\grave{\alpha} \mu \alpha \tau \eta \dot{\sigma}$ dalam bentuk Aorist Active Subjunctive. Dalam hal ini, kata kerja Aorist subjunctive menunjukkan potensi atau probabilitas. Dengan demikian, penulis Injil Matius ingin memberikan sebuah penekanan bahwa saudara dalam komunitas jemaat memiliki potensi untuk berbuat dosa. Menarik untuk diperhatikan bahwa konsep dosa dalam ayat ini secara kontekstual tidak memiliki objek yang jelas atau dengan kata lain sangat umum sifatnya. ${ }^{11}$ Tidak ada indikasi dosa spesifik (mencuri, berzinah, dll.) yang dapat ditemukan dalam teks ini. Dengan demikian yang menjadi penekanan disini bukanlah jenis dosa apa yang akan dilakukan jemaat. Pokok permasalahan dalam teks ini adalah potensi seorang saudara (jemaat) dalam melakukan dosa dan ketika hal tersebut terjadi, ada satu prosedur yang harus dilakukan untuk menyikapi permasalahan tersebut.

Adanya perintah untuk pergi menunjukkan sebuah gagasan bahwa seseorang yang mengetahui atau melihat saudaranya yang berdosa harus menanggapinya secara aktif. Ia harus mengusahakan pertemuan secara pribadi dengan saudara yang mela-

10 D A deSilva, An Introduction to the New Testament: Contexts, Methods \& Ministry Formation (InterVarsity Press, 2018).

${ }^{11}$ R T France, The Gospel of Matthew (Wm. B. Eerdmans Publishing, 2007). 


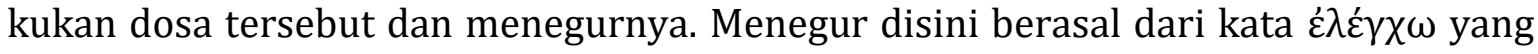
berarti memberitahukan yang salah atau meminta penjelasan. ${ }^{12}$ Dengan kata lain, diperlukan sebuah upaya untuk klarifikasi atau menyadarkan saudara yang berdosa ketika hal itu terjadi. Prosedur ini adalah prosedur standar dalam kebudayaan Yahudi yang memandang tindakan mempermalukan seseorang di depan umum sebagai sebuah dosa. ${ }^{13}$ Terlihat jelas bahwa konsep ini adalah wujud nyata Missio Dei yang menghampiri dan menebus dosa manusia. Teks sendiri menunjukkan secara gamblang melalui klausa kondisional bahwa penerapan prosedur ini memiliki dua respons yang mungkin dapat terjadi yaitu penolakan atau penerimaan. Jika saudara yang berbuat dosa mendengarkan teguran tersebut, ia akan "didapatkan" kembali. Sebaliknya, jika saudara yang berbuat dosa tidak menerima teguran dan usaha persuasif, maka diperlukan upaya tambahan.

Dalam hal ini, frasa mendapatkan saudaramu perlu mendapat perhatian khusus. Jika seseorang yang menjadi bagian dalam jemaat melakukan dosa, saudara ini berada dalam kondisi yang berbahaya. Dosa akan merusak hubungan (fellowship) seseorang dengan Allah dan berpotensi membuatnya hilang dan terpisah dari Allah. Konsep ini tentu sangat berhubungan dengan gagasan yang diusung dalam perumpamaan tentang domba yang hilang pada ayat 10-14. Potensi jemaat untuk melakukan dosa itu ada, namun Allah tidak menginginkan satu orang pun di antara jemaat terhilang dalam dosa (ay. 14). Itulah sebabnya diperlukan suatu countermeasure yang gereja harus lakukan ketika anggotanya melakukan dosa. Allah tidak ingin mereka hilang atau kehilangan fellowship dengan Allah. Inilah inti Missio Dei bagi jemaat yang jatuh dalam dosa. Itulah sebabnya seorang saudara yang lain, yang melihat saudaranya yang berdosa harus berusaha dengan aktif menegurnya secara pribadi. ${ }^{14}$ Melalui upaya ini, diharapkan saudara yang berdosa tersebut dapat ditemukan kembali. Hal ini didasari pemahaman bahwa dosa memisahkan seseorang dari umat Allah. ${ }^{15}$ Dengan kata lain, diperlukan upaya sungguh-sungguh agar saudara yang berdosa dapat dipulihkan kembali hubungannya dengan Allah dalam sebuah konteks relasi sebagai umat Allah.

Sebagaimana yang telah dijelaskan di atas, penelitian ini tidak hanya sampai pada tahap menemukan makna teks. Pertanyaan penting yang harus terjawab adalah apakah prosedur personal approach yang ada dalam Matius 18:15 ini dapat diterapkan dalam pelayanan gereja masa kini? Gereja modern pada umumnya menggunakan personal approach melalui pelayanan konseling dan cenderung "menunggu bola". Pendekatan yang cenderung pasif ini dapat diarahkan untuk lebih aktif agar dapat "menjemput bola" jika didapati ada isu jemaat yang melakukan dosa. Gereja

${ }^{12} \mathrm{~J}$ H Thayer, C L W Grimm, and C G Wilke, Thayer's Greek-English Lexicon of the New Testament: Coded with the Numbering System from Strong's Exhaustive Concordance of the Bible (Hendrickson Pub, 1996).

${ }^{13}$ C S Keener, The IVP Bible Background Commentary: New Testament (InterVarsity Press, 2014).

${ }^{14}$ W D Davies and Dale C Allison Jr, A Critical and Exegetical Commentary on the Gospel According to Saint Matthew, vol. 2 (T\&T Clark International, 2004).

${ }^{15}$ John Nolland, The Gospel of Matthew: A Commentary on the Greek Text (Michigan: W.B. Eerdmans, 2005). 
harus memiliki semangat yang sama dengan semangat Yesus. Tidak boleh ada anggota gereja yang terhilang dan oleh sebab itu prosedur personal approach haruslah diterapkan dengan bijak dan penuh kasih. Inilah implementasi nyata Missio Dei kepada jemaat yang berpotensi terhilang dalam dosa.

\section{Pendekatan Kolektif}

Matius 18:16,

Namun jika dia tidak mendengarmu (klausa kondisional)

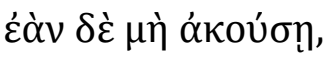

bawalah bersamamu satu atau dua orang (klausa perintah)

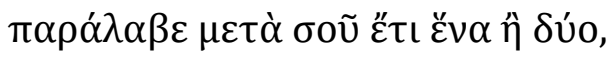

supaya melalui mulut dua atau tiga saksi setiap kata

dapat dipertanggungjawabkan. (klausa tujuan)

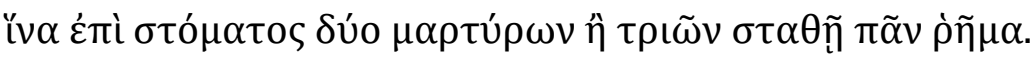

Ayat 16 menegaskan konsistensi gagasan perihal betapa pentingnya upaya untuk menyelamatkan saudara yang berbuat dosa agar dapat kembali pada fellowship dengan Allah. Ketika prosedur personal approach mengalami kegagalan, dibutuhkan prosedur lanjutan sebagai countermeasure agar upaya penyelamatan dapat terus berlangsung. Upaya ini kemudian dilakukan dengan menyiapkan prosedur kedua yang diharapkan dapat lebih berdampak. Prosedur kedua ini dilakukan dengan membawa satu atau dua orang tambahan yang akan berfungsi sebagai saksi. Prosedur ini berakar dari kebiasaan dalam Yudaisme yang juga tertuang dalam Ulangan 19:15.16 Dengan mengutip kebiasaan ini, Yesus menunjukkan adanya hubungan antara komunitas Israel Kuno dengan komunitas mesianik yang dibentuk olehnya. Tujuan dari penambahan saksi ini adalah agar setiap teguran yang disampaikan dan upaya mengoreksi saudara yang berbuat dosa dapat dipertanggungjawabkan. ${ }^{17}$ Selain itu, prosedur ini dilakukan dengan harapan agar saudara yang berdosa dapat melihat keseriusan dan kepedulian gereja dalam menasehati atau menegurnya. ${ }^{18}$

Dikutip dari Allison $^{19}$, teks ini memiliki kemiripan dengan Talmud yang berbunyi, "Samuel berkata: Siapapun yang bersalah terhadap saudaranya, ia harus berkata kepadanya, 'aku telah bersalah padamu'. Jika dia mendengarkanmu, hal itu baik. Jika tidak, biarlah ia membawa orang lain dan biarlah ia membela dirinya di depan mereka." Namun, dalam teks Talmud ini mereka yang bersalah yang aktif untuk melakukan sesuatu. Teks yang diadopsi Matius lebih cocok dengan tulisan dan kebiasaan yang tertuang dalam Gulungan Laut Mati, di mana para saudara lebih aktif mencari mereka yang bersalah. ${ }^{20}$ Dalam teks ini tidak diberikan suatu gambaran jelas

\footnotetext{
16 Ulrich Luz, "Matthew: A Commentary," in Hermeneia-a Critical and Historical Commentary on the Bible (Minneapolis: Augsburg, 2001).

17 John Nolland, The Gospel of Matthew: A Commentary on the Greek Text (W.B. Eerdmans, 2005).

18 Y L Tumanan, "Disiplin Gereja Berdasarkan Injil Matius 18:15-17 Dan Implementasinya Dalam Gereja Masa Kini," Jurnal Jaffray 15, no. ue 1 (2017): 31, https://doi.org/10.25278/jj71.v15i1.231.

${ }^{19}$ Davies and Allison Jr, A Critical and Exegetical Commentary on the Gospel According to Saint Matthew, vol. 2, p. .

${ }^{20}$ Ibid.
} 
mengenai siapa saksi yang dapat diajak untuk dapat menegur saudara yang berdosa tersebut. Satu hal yang pasti, orang-orang ini adalah bagian dari jemaat atau komunitas orang percaya yang dapat dipercaya. ${ }^{21}$ Perlu diperhatikan penekanan bahwa orang-orang yang dibawa untuk menegur saudara yang berdosa disini harus dapat berfungsi sebagai saksi yang kata-katanya dapat dipertanggungjawabkan. Dalam konteks hukum, saksi adalah mereka yang menjadi saksi mata terhadap sebuah fakta. ${ }^{22}$ Dengan kata lain, saksi di sini adalah mereka yang mampu melihat dosa saudaranya dengan objektif dan memiliki suatu dorongan yang sama untuk menyelamatkan saudara yang berdosa tersebut.

Tujuan diadakannya collective approach sebagai satu bentuk eskalasi prosedur adalah semata-mata agar saudara yang berdosa tersebut dapat "ditemukan" kembali. Dosa adalah masalah yang serius karena memiliki kemampuan untuk membuat saudara dalam sebuah jemaat hilang dan berada di luar fellowship dengan Allah. Dalam hal ini, terlihat jelas konsistensi konsep Missio Dei bagi jemaat yang jatuh dalam dosa. Itulah sebabnya diperlukan sebuah rancangan countermeasure yang serius dengan melakukan eskalasi dari personal approach (jika gagal) menjadi collective approach yang memiliki efektivitas lebih tinggi. Melalui collective approach, saudara yang berdosa diharapkan dapat melihat bagaimana gereja memandang dosa sebagai hal yang serius dan bagaimana keselamatan dirinya dalam fellowship dengan Allah adalah hal yang dipandang sebagai utmost importance di mata Allah, inilah semangat Missio Dei yang indah.

Penerapan prosedur collective approach dalam gereja modern tentu feasible. Kunci dalam menerapkan prosedur ini adalah saksi yang memiliki integritas dan reputasi yang baik sekaligus mengasihi saudaranya yang berdosa. Orang-orang ini adalah mereka yang mengharapkan keselamatan saudaranya yang berdosa dan bukan mereka yang berniat mempermalukan saudaranya. Dengan kata lain, gereja membutuhkan orang-orang yang memiliki reputasi dan integritas yang baik untuk dapat menerapkan prosedur ini. Selain itu, gereja juga membutuhkan mereka yang memiliki konsep Missio Dei yang sama sebagaimana yang dimiliki Allah, yang mengasihi orang yang berdosa, baik itu non-Kristen maupun mereka yang sudah percaya.

\section{Pendekatan Kongregasional}

Mat 18:17

Jika ia tidak mendengarkan mereka (klausa kondisional)

ćòv $\delta \dot{\varepsilon} \pi \alpha \rho \alpha \kappa o u ́ \sigma \eta ~ \alpha u ́ \tau \tilde{\omega} \nu$,

bicaralah kepada jemaat (klausa imperatif)

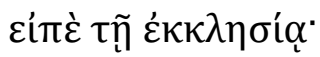

namun jika dia tidak mendengarkan jemaat

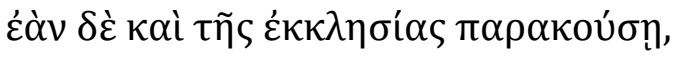

${ }^{21}$ William W Klein, Craig L Blomberg, and Robert L Hubbard Jr, Introduction to Biblical Interpretation 1 (Literatur SAAT, 2016).

22 G Kittel, G Friedrich, and G W Bromiley, Theological Dictionary of the New Testament: Abridged in One Volume (Wm. B. Eerdmans Publishing, 1985). 
jadikanlah dia bagimu selayaknya gentile dan pemungut cukai

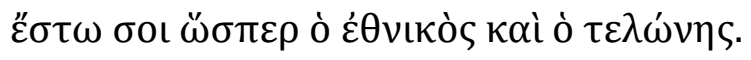

Bagian ini adalah puncak prosedur manajemen dosa dalam jemaat. Jika dengan menghadirkan saksi-saksi tidak mampu menyadarkan saudara yang berdosa tersebut, eskalasi isu akan mencapai tahap puncak. Isu ini kemudian akan disampaikan kepada jemaat dan jemaat akan melakukan hal yang sama dengan prosedur-prosedur sebelumnya. Jemaat dalam hal ini harus menegur dan menasehati saudara yang berdosa ini dengan satu motivasi yang sama, yaitu untuk menyelamatkan dan memulihkan dia. Dengan menghadirkan jemaat secara keseluruhan sebagai saksi untuk menegur dan menasehati, isu saudara yang melakukan dosa ini dieskalasi ke dalam tahap klimaks. Melalui prosedur ini, saudara yang berdosa, walaupun hanya satu orang, diperlakukan dengan utmost importance dalam komunitas jemaat. Melalui congregational approach, prosedur ini ingin mengajak saudara yang berdosa untuk melihat betapa berbahayanya dosa tersebut dan betapa komunitas jemaat memperdulikan keselamatan saudara tersebut. Langkah final ini diharapkan menjadi satu pendekatan terakhir yang dapat digunakan untuk menyadarkan saudara yang berdosa agar dapat bertobat dan kembali kepada Allah. Ironisnya, prosedur ini diprediksi masih dapat mengalami jalan buntu sehingga diperlukan suatu prosedur lagi demi menjaga integritas dan keutuhan jemaat yaitu pendisiplinan.

Saudara yang berdosa namun menolak nasehat dan seruan untuk bertobat yang telah diupayakan oleh gereja melalui tiga prosedur di atas harus menerima pendisiplinan. Ia harus mengalami excommunication, sebuah perlakuan di mana ia harus dipandang bukan lagi bagian dari komunitas gereja. ${ }^{23} \mathrm{Hal}$ ini dengan sangat gamblang dijelaskan melalui penggunaan terminologi gentile (orang yang tidak mengenal Allah) dan pemungut cukai yang merupakan simbol orang berdosa. Dengan demikian, saudara yang menolak untuk bertobat tersebut tidak lagi menjadi bagian dari komunitas gereja atau diekskomunikasi. ${ }^{24}$ Gereja adalah komunitas orang-orang yang telah menerima karya penebusan Kristus dan merupakan pribadi-pribadi yang berada dalam proses pengudusan. Sekalipun memiliki potensi berbuat dosa, orang-orang yang terhisab dalam gereja adalah mereka yang bersedia untuk bertobat jika mereka melakukan dosa. Ketika seseorang tidak bersedia bertobat dari dosa mereka, otomatis orang tersebut tidak memiliki tempat dalam gereja karena perbedaan nilai-nilai. Keberadaan orang-orang yang tidak memiliki value yang sama dalam gereja hanya akan mengacaukan integritas dan kesatuan gereja yang berisi orang-orang yang telah diselamatkan dan berjuang dalam proses pengudusan yang sama.

Dalam konteks gereja modern, prosedur congregational approach memerlukan sedikit penyesuaian tanpa menghilangkan esensinya. Beberapa gereja modern memiliki jumlah anggota yang sangat banyak dan menjadi kurang bijaksana jika dosa seorang saudara dibicarakan dalam pertemuan yang berisi ribuan orang dengan latar

${ }^{23}$ D A Carson, Matthew (Zondervan, 2017).

${ }^{24}$ Luz, "Matthew: A Commentary"; Davies and Allison Jr, A Critical and Exegetical Commentary on the Gospel According to Saint Matthew, vol. 2, p. . 
belakang dan pemahaman Alkitab yang berbeda. Keadaan ini tentu saja memiliki resiko tinggi yang mendorong terjadinya penyimpangan (gosip, dll.). Solusi yang bisa ditawarkan adalah dengan menerapkan prosedur congregational approach ini pada level komunitas sel atau kelompok kecil. Dengan demikian, penerapan prosedur ini dilakukan dalam jumlah partisipan yang masih dapat dikontrol dan dipastikan integritas dan reputasinya masing-masing. Di sisi lain, penerapan disiplin merupakan sebuah prosedur yang mutlak diperlukan. Pemahaman yang mendalam akan penerapan disiplin yang konsisten mendorong kesatuan gereja dan berhasilnya pelayanan gereja. 25

\section{KESIMPULAN}

Pada realitanya setiap anggota gereja tanpa memandang jabatan dan posisinya, baik itu jemaat, aktivis, dan pendeta sekalipun, memiliki potensi untuk melakukan dosa. Matius 18:15-17 telah memberikan satu countermeasure dalam perspektif Missio Dei yang alkitabiah dan aplikatif untuk dapat diterapkan dalam komunitas gereja sebagai satu bentuk manajemen gereja yang baik. Dosa adalah sebuah masalah yang berbahaya baik bagi kehidupan jemaat secara individu maupun secara kolektif. Itulah sebabnya diperlukan countermeasure yang tepat dalam menghadapi isu tersebut. Allah sangat mengasihi jemaat-Nya dan tidak menginginkan satupun dari antara mereka yang terhilang dan berada di luar fellowship dengan-Nya. Inilah Missio Dei yang memiliki dimensi yang holistik, tidak hanya bagi mereka yang non-Kristen namun juga bagi mereka yang sudah Kristen namun jatuh dalam dosa. Itulah sebabnya jika ada saudara yang berbuat dosa dalam komunitas gereja, seseorang yang memiliki reputasi dan integritas yang baik haruslah menerapkan personal approach dengan menegur saudara tersebut secara empat mata dan berusaha menasehati dia agar bertobat. Jika ia tidak menanggapinya dengan baik, bawalah satu atau dua orang saksi dari komunitas gereja yang memiliki reputasi dan integritas yang baik dan juga mengasihi saudara yang berdosa tersebut. Melalui teguran dan nasihat dalam collective approach ini diharapkan saudara yang berdosa tersebut dapat bertobat. Jika memang saudara tersebut masih belum bertobat, bawalah isu ini ke dalam kelompok kecil yang berisi orang-orang yang memiliki reputasi yang baik dan integritas yang teruji. Dengan prosedur congregational approach ini diharapkan saudara yang melakukan dosa ini dapat bertobat sehingga tidak memerlukan prosedur berikutnya yang adalah pendisiplinan. Jika memang saudara tersebut masih menolak niat tulus di balik nasehat dan teguran dalam congregational approach, maka tidak ada jalan lain selain melakukan pendisiplinan kepada saudara tersebut. Komunitas gereja harus melakukan disiplin dengan mengeluarkan saudara tersebut dari komunitas gereja demi menjaga integritas dan kesatuan jemaat. Dalam segala hal, Missio Dei haruslah terlihat dalam setiap gerak dan kebijakan komunitas kristen atau gereja.

${ }^{25}$ K H Song, "The Biblical Principle of Church Discipline and Its Application," Presbyterion 43, no. 2 (2017): 162. 


\section{REFERENSI}

Anthony, Michael J. "THE HEART OF GOD AND THE CHURCH.” Bibliotheca sacra 176, no. 704 (October 2019): 387-399. http://www.dts.edu/ (Publisher's URL:).

Carson, D A. Matthew. Zondervan, 2017.

Davies, W D, and Dale C Allison Jr. A Critical and Exegetical Commentary on the Gospel According to Saint Matthew. Vol. 2. T\&T Clark International, 2004.

deSilva, D A. An Introduction to the New Testament: Contexts, Methods \& Ministry Formation. InterVarsity Press, 2018.

France, R T. The Gospel of Matthew. Wm. B. Eerdmans Publishing, 2007.

Keener, C S. The IVP Bible Background Commentary: New Testament. InterVarsity Press, 2014.

Kittel, G, G Friedrich, and G W Bromiley. Theological Dictionary of the New Testament: Abridged in One Volume. Wm. B. Eerdmans Publishing, 1985.

Klein, William W, Craig L Blomberg, and Robert L Hubbard Jr. Introduction to Biblical Interpretation 1. Literatur SAAT, 2016.

Knoetze, J. "Perspectives on Family and Youth Ministry Embedded in the Missio Dei an African Perspective." Die Skriflig/In Luce Verbi 49, no. 1 (2015): 9. https://doi.org/10.4102/ids.v49i1.1874.

Luz, Ulrich. "Matthew: A Commentary." In Hermeneia-a Critical and Historical Commentary on the Bible. Minneapolis: Augsburg, 2001.

Nolland, John. The Gospel of Matthew: A Commentary on the Greek Text. Michigan: W.B. Eerdmans, 2005.

- - - The Gospel of Matthew: A Commentary on the Greek Text. W.B. Eerdmans, 2005.

Orobator, A E (Agbonkhianmeghe Emmanuel). "Between Ecclesiology and Ethics: Promoting a Culture of Protection and Care in Church and Society." Theological Studies 80, no. 4 (December 2019): 897-915. http://tsj.sagepub.com/ (Subscriber access).

Schipper, J. “The Anchor Yale Bible," 2008.

Song, K H. "The Biblical Principle of Church Discipline and Its Application." Presbyterion 43, no. 2 (2017): 162.

Thayer, J H, C L W Grimm, and C G Wilke. Thayer's Greek-English Lexicon of the New Testament: Coded with the Numbering System from Strong's Exhaustive Concordance of the Bible. Hendrickson Pub, 1996.

Tumanan, Y L. "Disiplin Gereja Berdasarkan Injil Matius 18:15-17 Dan Implementasinya Dalam Gereja Masa Kini." Jurnal Jaffray 15, no. ue 1 (2017): 31. https://doi.org/10.25278/jj71.v15i1.231.

Engelsviken, Tormod. "MISSIO DEI : THE UNDERSTANDING AND MISUNDERSTANDING OF A THEOLOGICAL CONCEPT IN EUROPEAN CHURCHES AND MISSIOLOGY." International Review of Mission 92, no. 367 (October 2003): 481-497.

Richebächer, Wilhelm. "MISSIO DEI: THE BASIS OF MISSION THEOLOGY OR A WRONG PATH?" International Review of Mission 92, no. 367 (October 2003): 588-605.

Soo-il, Chai. "MISSIO DEI -ITS DEVELOPMENT AND LIMITATIONS IN KOREA." International Review of Mission 92, no. 367 (October 2003): 538-549.

“Dinamika Hidup Generasi Muda Kristen Indonesia.” Accessed May 10, 2021. http://bilanganresearch.com/dinamika-hidup-generasi-muda-kristenindonesia.html. 